\title{
NEW-ONSET ATRIAL FIBRILLATION IN THE POST-PRIMARY PCI SETTING: A SYSTEMATIC REVIEW
}

\author{
F. Al-Obaidi ${ }^{1,2}$, T. Al-Kinani ${ }^{1,2}$, M. H. Al-Ali',2, M. H. Al-Myahi² \\ ${ }^{1}$ University of Thi Qar/College of Medicine - Iraq \\ ${ }^{2}$ Nasiriya Heart Centre - Iraq
}

\begin{abstract}
Background: Atrial fibrillation is a relatively common complication of acute myocardial infarction with significant impact on the short and long-term prognosis. Methods: A systematic literature review was done through Pubmed and CENTRAL to extract data related to new-onset atrial fibrillation following primary PCl. Results: Searching resulted in twenty-one matched studies. Extraction of data showed an incidence rate of new-onset atrial fibrillation (2.8\%-58\%). A negative impact was found on the outcomes of patients treated with primary $\mathrm{PCl}$ with increased short and long-term mortality and morbidity. Conclusion: New-onset atrial fibrillation is an adverse prognostic marker in patients with acute myocardial infarction treated invasively. Preventive measures and anticoagulant therapy should be considered more intensively in this subset of patients.
\end{abstract}

Key words: atrial fibrillation, new-onset atrial fibrillation, myocardial infarction, percutaneous coronary intervention, primary $\mathrm{PCl}$

Corresponding author: Dr. Firas Al-Obaidi, FIBMS, CAMBS, Thi Qar University-College of Medicine, Nasiriya Heart Centre, e-mail: firasrobaidi@gmail.com, tel: +9647726663279

\section{INTRODUCTION}

A trial fibrillation (AF) is a relatively common complication of acute myocardial infarction with an estimated incidence of new-onset AF (NOAF) ranging from $2.3 \%$ to $28 \%[1,2]$. It is possible that myocardial infarction induces structural and electrophysiological changes in the atrial tissue that act as a substrate for the initiation of AF [3]. The adverse hemodynamic effects of atrial fibrillation are related to tachycardia, which leads to increased oxygen demand and reduced diastolic filling time. Furthermore, the elevated heart rate and decreased blood pressure are associated with ineffective atrial contractions and impaired $\mathrm{AV}$ synchrony causing further deterioration in coronary perfusion and exacerbation of the myocardial ischemia.
The impact of NOAF on the acute coronary syndrome patients is significant, with impaired short and long-term prognosis. The Global Registry of Acute Coronary Events (GRACE) substudy reported that patients with NOAF had a higher in-hospital and 6-month mortality and morbidity than patients without $A F$, equal to the patients with prior AF [4]. A meta-analysis of 43 studies indicated that mortality is higher in acute STEMI patients with NOAF (OR 1.37; $95 \% \mathrm{Cl}, 1.26$ to 1.49 ) and the risk remained elevated even after adjustment for age, diabetes mellitus, hypertension, prior MI, heart failure and coronary revascularization [5]. However, confounding effects on the mortality of acute STEMI with NOAF in comparison with those without AF are possible due to baseline LV dysfunction, higher Killip class and cardiogenic shock 
[6]. Morbidity is also higher in patients with NOAF due to the increased risk of LV dysfunction, stroke and bleeding events [7].

This review explores the available evidence on the incidence and major predictors of NOAF, and highlights its prognostic significance in invasively treated acute STEMI patients.

\section{SEARCH METHODOLOGY}

A literature search through PubMed and Cochrane CENTRAL library was done using the MeSH terms "atrial fibrillation and myocardial infarction" and "atrial fibrillation and primary PCl”. In addition, manual search of relevant references was done. The search was limited to papers in the English language only. The initial search resulted in $\mathbf{5 7 3 9}$ matches followed by removal of duplicates, screening of titles and abstracts and finally exploring the full text of relevant papers. Finally, 21 papers, investigating specifically the risk of new-onset AF post primary $\mathrm{PCl}$, were selected for data extraction and inclusion in this systematic review (Fig. 1). The included research types are substudies of prospective trials $(n=6)$, prospective registries and cohorts $(n=5)$, and retrospective analyses $(n=10)$.

\section{NEW-ONSET AF POST PRIMARY PCI}

The development of new-onset $\mathrm{AF}$ after $\mathrm{PCl}$ is defined by the European Society of Cardiology as "the change from sinus rhythm at admission to AF during/ after PCl" typically occurring during the first four days after acute MI" [8]. Several studies evaluated the clinical impact of NOAF in the contemporary era following the advancements in the management of acute STEMI including reperfusion by the widespread application of invasive coronary catheterization.

Although no direct comparison is available regarding the incidence of NOAF between primary $\mathrm{PCl}$ and thrombolytic therapy, the rate of NOAF was lower after primary $\mathrm{PCl}(18 \%)$ than that following thrombolytic therapy $(33 \%)$ [9]. It has been suggested that primary $\mathrm{PCl}$ is superior to thrombolytic therapy in lowering the incidence of NOAF, especially when higher TIMI flow grade can be achieved [10]. In a study of patients with inferior MI, transient NOAF was reported in $17 \%$ of patients who underwent primary $\mathrm{PCl}$, and in $39 \%$ of those who received thrombolytic therapy [11]. Another study showed a $49.8 \%$ risk of NOAF with thrombolytic therapy and $25.6 \%$ with primary PCl [12].

The studies that enrolled patients treated with primary $\mathrm{PCl}$ were heterogeneous, and many of them were non-randomised observational studies with variations in follow-up duration and analysis methodology. There are differences regarding definitions of time of onset and the type and duration of AF attacks resulting in inconsistencies of some of the results. Furthermore, there is insufficient data regarding management strategies and the impact of antithrombotic therapy.

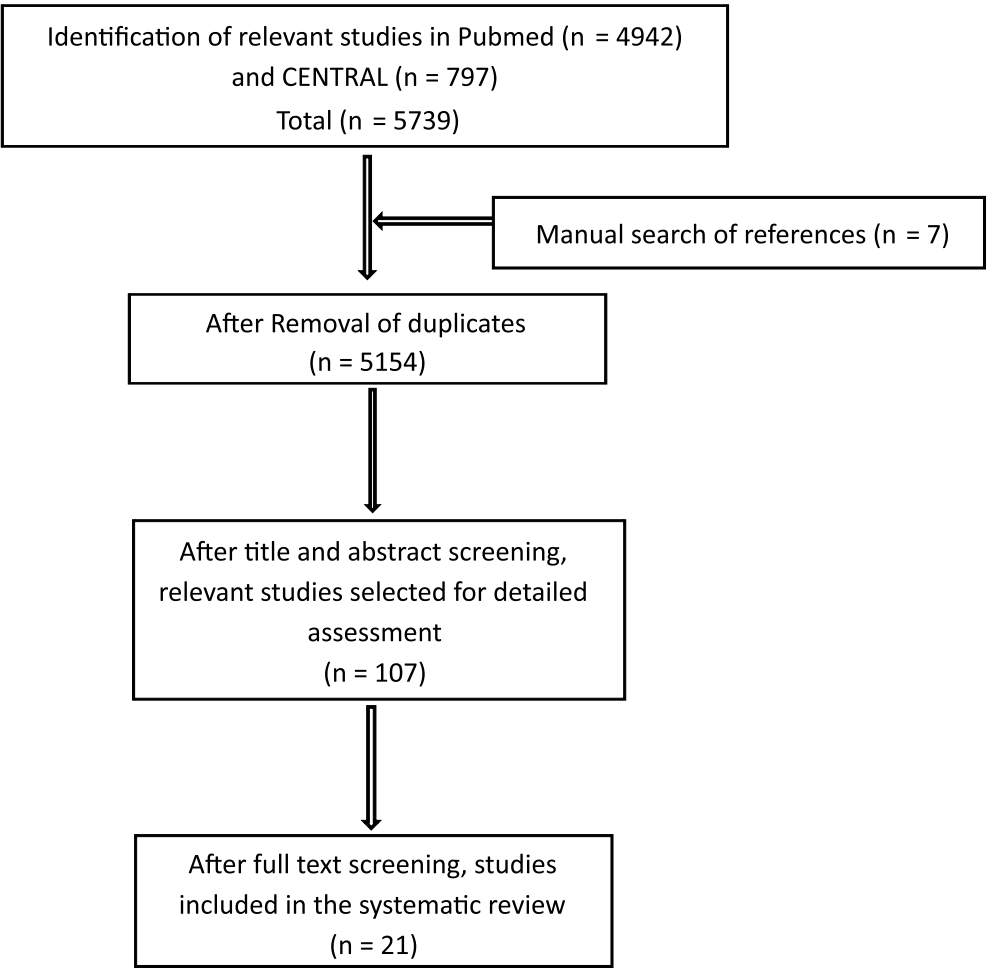

Fig. 1. Overview of the searching process 


\section{THE INCIDENCE OF NEW-ONSET AF}

Studies of AF in patients with acute STEMI managed by primary $\mathrm{PCl}$ showed an incidence rate ranging from $2.8 \%$ to $58 \%$ (Table 1) [13-33]. The incidence rate of NOAF in the large prospective studies (the OACIS, APEX-AMI, RISK-PCI and HORIZONS-AMI trials) is ranging from $4.0 \%$ to $7.7 \%[13,14,18,19]$. Most cases of NOAF are transient or paroxysmal. However, persistent AF at hospital discharge was $5.3 \%$ in one study [14].

The variation in the incidence of NOAF can be explained by the lack of standard definitions in the assessment of NOAF. The timing of detection, the intensity of patient monitoring and duration of follow-up were variable between studies. Some studies considered AF on admission without prior history as NOAF
$[13,18]$, while others estimated the incidence only during hospitalization. Most studies used standard ECG monitoring throughout the period of hospitalization, while investigators of the ARREST study used implantable cardiac monitors for extended periods of time reaching up to 2 years counting all episodes of $\mathrm{AF}$, including short-lived asymptomatic events, which are the reason of a very high rate of NOAF in this study (58\%) [31]. In contrast, another study performed a single ECG, 3 hours after primary PCI [16]. In addition, some studies did not differentiate between AF preceding acute STEMI and that occurring later. Two large retrospective registries in the USA and South Korea reported AF in $8.7 \%$ and $4.3 \%$ of the patients' population, respectively. However, neither studies discriminated between prior $\mathrm{AF}$ and post-primary PCI NOAF [24, 25].

Table 1. Summary of studies of NOAF post primary PCI

\begin{tabular}{|c|c|c|c|c|c|}
\hline Study & $\begin{array}{l}\text { No. of } \\
\text { patients }\end{array}$ & $\begin{array}{l}\text { Incidence of } \\
\text { NOAF (n) }\end{array}$ & Type of study & Duration of follow-up & $\begin{array}{l}\text { Country and year } \\
\text { of publication }\end{array}$ \\
\hline Kinjo (13) & 2,475 & $7.7 \%(190)$ & $\begin{array}{l}\text { Prospective, part of the } \\
\text { OACIS study }\end{array}$ & 1 year & Japan, 2003 \\
\hline Lopes (14) & 5,745 & $6.3 \%(342)$ & $\begin{array}{l}\text { Prospective, part of the } \\
\text { APEX-AMI trial }\end{array}$ & 90 days & Multi-centre, 2009 \\
\hline $\operatorname{Lin}(15)$ & 783 & $4.3 \%(33)$ & Prospective study & 30 days & Taiwan, 2011 \\
\hline Beukema (16) & 2,134 & $3.0 \%(52)$ & Retrospective registry & 18 months & Netherland, 2012 \\
\hline Asanin (17) & 180 & $5.0 \%(9)$ & Prospective registry & NA & Serbia, 2012 \\
\hline Mrdovic (18) & 2,096 & $4.0 \%(85)$ & $\begin{array}{l}\text { Prospective, a substudy of } \\
\text { the RISK-PCI trial }\end{array}$ & 1 month & Serbia, 2012 \\
\hline Rene (19) & 3,281 & $4.5 \%(147)$ & $\begin{array}{l}\text { Prospective, sub study of the } \\
\text { HORIZONS-AMI trial }\end{array}$ & 36 months & Multi-centre, 2014 \\
\hline Gal (20) & 830 & $8.8 \%(73)$ & $\begin{array}{l}\text { Prospective, a substudy of } \\
\text { the On-TIME II trial }\end{array}$ & 1 month & Multi-centre, 2015 \\
\hline Zehir (21) & 1,553 & $5.8 \%(90)$ & Retrospective & NA & Turkey, 2016 \\
\hline Karataş (22) & 621 & $6.4 \%(40)$ & Retrospective & 22 months & Turkey, 2016 \\
\hline Olsen (23) & 373 & 6\% (24) & Prospective single center & 5.5 years & Denmark, 2016 \\
\hline Garg (24) & $1,493,859$ & $8.7 \%(129,354)$ & Retrospective registry & In-hospital & USA. 2017 \\
\hline Hwang (25) & 5,356 & $4.3 \%(119)$ & Retrospective registry & 1 year & South Korea, 2017 \\
\hline Karabağ (26) & 1,057 & $5.4 \%(58)$ & Retrospective study & \begin{tabular}{|l|}
$33.16 \pm$ \\
13.2 months
\end{tabular} & Turkey, 2017 \\
\hline Topaz (27) & 1,657 & $2.8 \%(47)$ & Retrospective & $3.4 \pm 2.1$ years & Israel, 2017 \\
\hline Podolecki (28) & 4,099 & $5.5 \%(225)$ & Prospective registry & 135 months & Poland, 2017 \\
\hline Rencuzogullari (29) & 1,565 & $5.8 \%(86)$ & Retrospective & $30.8 \pm 16.3$ months & Turkey, 2017 \\
\hline Rhyou (30) & 527 & $15.4 \%(81)$ & Retrospective & 1 year & Korea, 2018 \\
\hline Romanov (31) & 50 & $58 \%(29)$ & $\begin{array}{l}\text { Prospective observational } \\
\text { (the ARREST) study }\end{array}$ & 2 years & Netherland, 2018 \\
\hline Mazzone (32) & 1135 & $7.7 \%(88)$ & Retrospective & 2 years & Italy, 2018 \\
\hline Modin (33) & 373 & $6 \%(24)$ & $\begin{array}{l}\text { Prospective } \\
\text { (single centre) }\end{array}$ & 5.6 years & Denmark, 2018 \\
\hline
\end{tabular}




\section{PREDICTORS OF NEW-ONSET AF}

Several studies aimed at identifying clinical variables that independently predict NOAF in STEMI patients. Analysis of data showed that independent predictors of NOAF following primary $\mathrm{PCl}$ were advancing age $[13,16,18,19,21,22,27,29,30,32]$ and signs indicating extensive myocardial damage indicated by tachycardia [13, 22], hypotension [18], cardiogenic shock [30], higher Killip class [13, 16, $18,21]$ and poor LV function (represented by LV EF) [21, 22, 29].

The studies found a predictive relationship between laboratory parameters and subsequent incidence of NOAF. A strong association was found with elevated cardiac biomarkers including troponin and BNP [17, $21,26,31,32]$. Various hematological indices were regarded as predictors of the NOAF development $[21,22,32]$.
Angiographic characteristics of the infarct-related artery including total occlusion, final low TIMI flow [18], the RCA as the culprit artery [16], complexity of coronary artery lesions represented by Syntax score, and the Syntax score II [29] as well as failed PCI procedures [21] were frequently found in patients with NOAF.

Other reported predictors are a previous history of MI [27] and revascularization [21], male gender [13], impairment of renal function [18], body mass index [19, 32], LA size [22, 30] and function [33] by echocardiography, and a higher CHA2DS2VASc score [31].

\section{PROGNOSTIC IMPACT AND EFFECT ON OUTCOMES}

The effect of NOAF was evident in both the short and long-term outcomes of patients after primary $\mathrm{PCl}$. Although the studies varied in their follow-up duration and discrepancies were noticed in some of the re-

Table 2. Predictors of NOAF post primary PCI

\begin{tabular}{|l|l|}
\hline Study & Predictors \\
\hline Kinjo [13] & Age, male gender, heart rate $\geq 100$ bpm, and Killip class IV \\
\hline Lopes [14] & NA \\
\hline Lin [15] & NA \\
\hline Beukema [16] & Age, Killip class > 1, and occluded RCA \\
\hline Asanin [17] & BNP $\geq 720 \mathrm{pg} / \mathrm{mL}$ \\
\hline Mrdovic [18] & $\begin{array}{l}\text { Age, systolic blood pressure }<100 \mathrm{~mm} \mathrm{Hg}, \text { Killip class }>\text { I, creatinine clearance }<60 \text { ml/min, occluded } \\
\text { infarct-related artery, TIMI blood flow < III }\end{array}$ \\
\hline Rene [19] & Age and body mass index \\
\hline Gal [20] & NA \\
\hline Zehir [21] & $\begin{array}{l}\text { Age, Peak Troponin I, Previous CABG, Killip 3/4 on admission, Unsuccessful PCl, } \\
\text { LV EF, CRP }\end{array}$ \\
\hline Karataş [22] & $\begin{array}{l}\text { Age, LV EF, LA volumes, admission heart rate, multivessel disease, increased levels of CRP, mean platelet } \\
\text { volume, red cell distribution width, uric acid, neutrophil to lymphocyte ratio and monocyte to high-density } \\
\text { lipoprotein ratio }\end{array}$ \\
\hline Olsen [23] & Global longitudinal strain by echocardiography \\
\hline Garg [24] & NA \\
\hline Hwang [25] & NA \\
\hline Karabağ [26] & Plasma BNP \\
\hline Topaz [27] & Age and prior Ml \\
\hline Podolecki [28] & NA \\
\hline Rencuzogullari [29] & Age, LV EF, Syntax score and Syntax score II \\
\hline Rhyou [30] & Cardiogenic shock left atrial volume index and age \\
\hline Romanov [31] & Baseline troponin level and CHA2DS2VASc score of 4 \\
\hline Mazzone [32] & Advanced age, leukocyte count > 9.68 $\times 103 / \mu L$, BNP > 80 ng/L and obesity \\
\hline Modin [33] & Echocardiography parameters: left atrial emptying fraction (LAEF) and left atrial expansion index (LAi) \\
\hline
\end{tabular}


sults, the overall evidence indicates worse outcomes with the development of NOAF.

A prospective study of 2,475 patients with acute STE$\mathrm{MI}$ who underwent primary $\mathrm{PCl}$ showed poor longterm outcomes in the patients with NOAF. Although adverse events during hospitalization (LV dysfunction, cardiogenic shock, stroke, and ventricular arrhythmias) were significantly higher in patients with AF, adjusted short-term mortality was not different from the patients without AF. However, a higher longterm mortality at 12 months was reported with NOAF after adjustment for other clinical variables (HR 3.04, $95 \% \mathrm{Cl} 1.24$ to 7.48 ) [13].

In the randomized controlled APEX-AMI trial, a three month follow-up of patients after acute STEMI showed higher mortality with NOAF (adjusted HR
$1.81 ; 95 \% \mathrm{Cl} 1.06-3.09 ; \mathrm{P}=0.029)$. Other short-term complications have been significantly associated with NOAF including congestive heart failure, shock, and stroke [14].

An assessment of outcomes in 2,134 acute STEMI patients was done to detect differences between the patients with prior AF (detected on admission) and those with NOAF following primary $\mathrm{PCl}$ (detected 3 hours after admission). A follow-up for 18 months showed that both prior AF and NOAF were associated with increased long-term mortality, 21\%, and $23 \%$, respectively. However, the adjusted risk of mortality was significantly elevated only in the presence of NOAF (OR 3.69, 95\% Cl 1.87-7.29) [16].

The RISK-PCI trial found a significant correlation between the incidence of NOAF, the short-term mortal-

Table 3. Outcomes of NOAF post primary PCI

\begin{tabular}{|c|c|c|}
\hline Study & $\begin{array}{l}\text { Short-term mortality } \\
\text { (vs. patients without AF) }\end{array}$ & $\begin{array}{l}\text { Long-term mortality } \\
\text { (vs. patients without AF) }\end{array}$ \\
\hline Kinjo [13] & $\begin{array}{l}16.0 \% \text { vs } 6.7 \%, p<0.001 . \text { Adjusted HR } 1.42(95 \% \mathrm{Cl} \\
(0.88-2.31), p=0.153)\end{array}$ & $\begin{array}{l}\text { 18.9\% vs } 7.9 \% ; p<0.001 . \text { Adjusted HR1.64 } \\
(95 \% \mathrm{Cl} 1.05-2.55, p=0.03)\end{array}$ \\
\hline Lopes [14] & Adjusted HR $1.81(95 \% \mathrm{Cl} 1.06-3.09 ; p=0.029)$ & NA \\
\hline Lin [15] & $\begin{array}{l}\text { HR } 2.344(95 \% \mathrm{Cl} 0.982-5.596) \\
p \text { (Univariate analysis) }=0.055 \\
p \text { (Multivariate analysis) }=0.530\end{array}$ & NA \\
\hline Beukema [16] & NA & $\begin{array}{l}\text { 23\% vs } 4.7 \%, p=0.001 . \text { Adjusted OR } 3.69 \text {, } \\
(95 \% \text { Cl 1.87-7.29) }\end{array}$ \\
\hline Asanin [17] & NA & NA \\
\hline Mrdovic [18] & $\begin{array}{l}22.5 \% \text { vs } 3.5 \% \text {. Adjusted OR } 2.67(95 \% \mathrm{Cl} 1.46- \\
4.89), p<0.001\end{array}$ & NA \\
\hline Rene [19] & NA & $\begin{array}{l}11.9 \% \text { vs } 6.3 \% . \mathrm{HR} 1.91(95 \% \mathrm{Cl} 1.16-3.14), \mathrm{p} \\
=0.009 .\end{array}$ \\
\hline Gal [20] & $\begin{array}{l}14.3 \% \text { vs } 1.4 \%, p<0.001 \text {. Adjusted OR 13.476, } p= \\
0.006 \text {. }\end{array}$ & NA \\
\hline Zehir [21] & NA & NA \\
\hline Karataş [22] & NA & $\begin{array}{l}27 \text { vs. } 5 \%, P<0.001 . \text { HR: } 2.20 \text { (95\% Cl 1.03- } \\
4.72), P=0.040\end{array}$ \\
\hline Olsen [23] & NA & NA \\
\hline Garg [24] & $\begin{array}{l}10.3 \% \text { vs } 9.4 \% \text {. Adjusted OR } 1.10(95 \% \mathrm{Cl} 1.06 \text { to } \\
1.16) ; p<0.0001)\end{array}$ & NA \\
\hline Hwang [25] & NA & $\begin{array}{l}22.7 \text { versus } 9.5 \%, \text { HR } 2.51(95 \% \mathrm{Cl} 1.68 \sim 3.76) \text {, } \\
P<0.001\end{array}$ \\
\hline Karabağ [26] & NA & $24.1 \%$ vs $7 \%, p=0.015$ \\
\hline Topaz [27] & $6.4 \%$ vs. $2.1 \%, p=0.08$ & $17 \%$ vs. $9.1 \%, p=0.07$ \\
\hline Podolecki [28] & $7.6 \%-27.4 \%$ vs $4.2 \%-6.3 \%, p<0.05$ & $12 \%-38.7 \%$ vs $9 \%-12.9 \%, p<0.05$ \\
\hline Rencuzogullari [29] & $\mathrm{NA}$ & $23.3 \%$ vs. $11 \% ; p=0.032$ \\
\hline Rhyou [30] & NA & NA \\
\hline Romanov [31] & $0.0 \%$ & $0.0 \%$ \\
\hline Mazzone [32] & NA & $\begin{array}{l}\text { HR } 2.885(95 \% \text { Cl 1.146-7.268), } \\
P=0.025\end{array}$ \\
\hline Modin [33] & NA & NA \\
\hline
\end{tabular}


ity (30 days) (adjusted OR 2.67, 95\% Cl 1.46-4.89, p $=0.001$ ) and the composite MACE rate (adjusted OR 2.39, 95\% Cl 1.47-3.87) but no significant association was noted with stroke, re-infarction, target vessel revascularization or major bleeding [18].

In the Harmonizing Outcomes With Revascularization and Stents in Acute Myocardial Infarction (HORIZONS-AMI) trial, a randomized multicenter trial, patients with NOAF post primary $\mathrm{PCl}$ had worse outcomes after three years follow-up. The patients with NOAF had a higher mortality in comparison with those without AF (11.9\% vs $6.3 \%, p=0.01)$. Similarly, the rates of reinfarction ( $16.4 \%$ vs $7.0 \%, p<0.0001)$, stroke $(5.8 \%$ vs $1.5 \%, p<0.0001)$, and major bleeding $(20.9 \%$ vs $8.2 \%, p<0.0001)$ were higher. Newonset AF was found to be an independent predictor of long-term mortality (HR 1.74, 95\% Cl 1.30 to 2.34, $\mathrm{p}=0.0002)$ and MACE rate (HR 1.73, 95\% Cl 1.27 to 2.36). Although there was no report of short-term outcomes, the Kaplan-Meier survival curve showed an early separation in outcomes rates between patients with and without AF, with poor outcomes in the patients with AF [19].

A substudy of the tirofiban in myocardial infarction evaluation (On-TIME) II study, a prospective, multicentre, placebo-controlled, randomized clinical trial with a total of 984 patients evaluated the relation of time of development of NOAF to outcomes. Multivariate analysis indicated that only AF developing within 24-72 hours after primary $\mathrm{PCl}$ was significantly associated with increased mortality (adjusted OR 13.476, $p=0.006)$. Older age, hypertension, diabetes, previous MI, blood pressure on admission, LV dysfunction and higher Killip class, < III TIMI flow after $\mathrm{PCl}$ and LAD as the culprit's vessel were the main clinical predictors of mortality in patients with NOAF [20].

A large registry including about 1.5 million acute STE$\mathrm{MI}$ patients in the USA assessed retrospectively the impact of AF, both prior and new-onset. The analysis indicated a higher mortality in patients with AF compared to those without AF (10.3\% vs. 9.4\%, adjusted OR 1.1, $\mathrm{Cl} 1.06-1.16, \mathrm{p}<0.0001)$. Higher rates of complications were reported during hospitalization of patients with AF including acute heart failure (33.0\%), cardiogenic shock (17.2\%), stroke (1.0\%), acute kidney injury $(12.8 \%)$, vascular complications $(1.4 \%)$, bleeding (4.0\%) and blood transfusion (5.0\%) [24].

Similarly, The Korean Acute Myocardial Infarction Registry indicated that presence of AF on admission represented a poor prognostic marker in patients with acute STEMI treated by primary $\mathrm{PCl}$ and was significantly associated with a higher 1-year all-cause mor- tality (HR 2.43, 95\% Cl 1.28-4.59, $\mathrm{P}=0.006)$. The patient outcomes were significantly higher with AF in comparison to sinus rhythm including all-cause mortality $(22.7$ vs $9.5 \%$, HR 2.51, 95\% Cl 1.68-3.76, P < 0.001 ), cardiac death (17.7 versus $7.5 \%$, HR 2.49, $95 \% \mathrm{Cl} 1.59-3.90, \mathrm{P}<0.001)$ and composite MACE (20.2 versus $13.8 \%$, HR 1.58, 95\% Cl 1.05-2.39, P $=0.030$ ), respectively. However, the registry did not provide data on stroke and bleeding risks [25].

Different results emerged from a retrospective study involving 1,657 patients. The mortality rates with NOAF, both long and short-term, were numerically higher $(6.4 \%$ vs. $2.1 \%, p=0.08$ and $17 \%$ vs. $9.1 \%, p=0.07$, respectively). The study showed that prior AF, but not NOAF, is correlated with short and long-term mortality [27].

The ARREST study, a prospective observational study, followed acute STEMI patients with preserved LV function after primary $\mathrm{PCl}$, using implantable cardiac monitors for a prolonged period (24 months). About $40 \%$ of NOAF cases were detected within the first six months after STEMI, and $93 \%$ of them were asymptomatic. The results showed that AF was not associated with higher mortality rates, stroke, and bleeding. However, there was an increase in the rate of hospitalization for HF, in the progression of angina and hypertensive crises: $13.8 \%$ vs. $4.8 \%$ in patients without AF. However, the study sample size was small (51 patients) and not powered to draw conclusions [31].

Evidence extracted from the above studies strongly suggests a significant association of impaired survival and increased adverse events in patients developing AF following acute STEMI managed invasively. However, more information is required regarding the duration and burden of AF attacks, whether it is causing symptoms or not, the profile of thrombotic risk, and the effect of AF management on patients' outcomes.

\section{RISK OF STROKE AND ANTICOAGULATION CHALLENGES}

The risk of stroke is significantly elevated in patients developing NOAF secondary to acute STEMI with rates of stroke in the first year about $10.2 \%$ [11], significantly associated with the duration of NOAF $(\geq 3.5$ hours) and with the recurrence of AF following the hospital discharge [34]. Although NOAF can be transient, a high rate of recurrence $(22 \%)$ was detected in patients with NOAF following acute STEMI [11, 3537] which may increase the possibility of developing stroke or TIA.

The independent predictors of recurrences are NOAF (adjusted HR 7.84, 95\% Cl 4.08-10.43, p < 0.0001); 
advanced age (HR 1.72, 95\% Cl 1.40-2.11, p < $0.0001)$; LVEF < 45\% (HR 1.89, 95\% Cl 1.19-3.02, $\mathrm{p}=0.007)$ and LA enlargement (HR 1.96, $95 \% \mathrm{Cl}$ 1.16-3.32, $p=0.01$ ) [36].

Assessment of MACE events following primary $\mathrm{PCI}$ complicated by AF indicated a significantly increased short and long-term risk of stroke. In-hospital stroke rate was found in Kinjo et al., 2.3\% with vs. $0.6 \%$ without AF, $p=0.002$ [13], and in the RISK-PCI trial it was $3.1 \%$ vs. $0.8 \%, p=0.03$ (18). Mid-term (90 days) stroke rate in the APEX-AMI trial was 9.2 (HR 2.98; 95\% Cl 1.47-6.04) $p=0.0024$ (14). In the HORIZONS-AMI trial, the long-term (3-year) stroke rate was $5.8 \%$ with vs. $1.5 \%$ without AF ( $p<0.0001)$ [19].

Anticoagulation treatment for transient NOAF is associated with a lower rate of stroke and TIA (6.3\% vs. 9.9\% with antiplatelet therapy) [36]. Anticoagulation treatment on discharge after acute STEMI can reduce the composite endpoint of death and non-fatal stroke (HR 0.33, 95\% Cl 0.11-0.96, p = 0.041) [35].

A limited number of studies evaluated the effect of anticoagulation on the prognosis of NOAF after primary $\mathrm{PCl}$. In the APEX-AMI trial, the use of triple therapy (warfarin plus DAPT) was associated with lower mortality $(0.0 \%$ vs. $5.1 \%$ with no antithrombotic therapy) and stroke rates $(2.7 \%$ vs. 5.1 without antithrombotic therapy) [14].

However, management of AF in acute coronary syndrome patients with coronary artery stenting is a clinical challenge as a reduction of ischemic events can be complicated by increased bleeding risk. A metaanalysis of 18 studies enrolling more than 20,000 patients with $\mathrm{AF}$ and $\mathrm{PCl}$ showed that triple therapy (including DAPT and an anticoagulant) in ACS increased the risk of bleeding (OR 0.68, 95\% Cl 0.56$0.82, \mathrm{P}<0.0001$ ) while the risk of MI, MACE, stroke and the all-cause mortality were similar to those receiving DAPT without anticoagulation [38].

Two large randomized controlled studies, the PIONEER AF-PCl trial and the RE-DUAL PCl trial assessed the bleeding risk in patients with non-valvular AF who underwent $\mathrm{PCl}$ using NOAC therapy. About $50 \%$ of patients in both studies were labelled as ACS patients. In the PIONEER AF-PCI trial, the bleeding risk was similar between triple therapy (rivaroxaban $2.5 \mathrm{mg}$ twice daily plus DAPT) and dual therapy (rivaroxaban $15 \mathrm{mg}$ once daily plus a P2Y12 inhibitor) $-18.0 \%$ vs. $16.8 \%$, respectively. Bleeding risk with both regimens using rivaroxaban was lower than warfarin plus DAPT (26.7\% with warfarin). The MACE rate (death from cardiovascular causes, MI or stroke) showed no significant differences between the three regimens [39]. In the RE-DUAL PCI trial, lower bleed- ing event rates were found with dual therapy (dabigatran plus a P2Y12 inhibitor) in comparison with triple therapy (warfarin plus DAPT) [40].

Based on the available evidence, we suggest consideration of using anticoagulants in high-risk patients with NOAF after primary $\mathrm{PCl}$ to lower the risk of mortality and morbidity in this patients' subset. High-risk features include advanced age, LV dysfunction, and higher Killip class on admission with a high CHADS2VASc score and low bleeding risk. Bleeding risk can be minimized by the application of the recent recommendations of the European Society of Cardiology in patients with $\mathrm{PCl}$ and an indication for anticoagulation. These include shortening of triple therapy duration or alternatively using dual therapy, use of low dose aspirin and clopidogrel as the P2Y12 inhibitor of choice and considering NOACs (rivaroxaban 15 mg or dabigatran $150 \mathrm{mg}$ ) as a substitute to warfarin [8].

\section{EVIDENCE GAP AND FUTURE DIRECTIONS}

The currently available evidence is far from providing definite recommendations. Many confounding factors exist including, but not limited to, the patients' heterogeneity, disease burden, relation of AF and NOAF to the pathophysiology of STEMI and primary $\mathrm{PCl}$, impact and necessity of rhythm control, factors (clinical, homeostatic, and angiographic) that determine prognosis, the type and duration of anticoagulation if needed, and risk of bleeding. Having in mind these burning issues, properly designed studies are still needed.

\section{CONCLUSION}

The impact of NOAF and its treatment poses a significant burden on the outcomes of primary $\mathrm{PCl}$. Based on data currently available in the literature, it can be concluded that the recognition of NOAF as an adverse prognostic factor is important for risk stratification of patients with acute STEMI. Intensification of preventive measures in high-risk patients and consideration of anticoagulation are needed in the management of patients with NOAF with more intensive short- and long-term follow-up and frequent follow-up visits aiming at improved morbidity and mortality.

\section{Disclosure: none to disclose}

Funding: no funding resources for this paper to declare 


\section{REFERENCES}

1. Schmitt J, Duray G, Gersh BJ, Hohnloser SH. Atrial fibrillation in acute myocardial infarction: a systematic review of the incidence, clinical features and prognostic implications. Eur Heart J. 2009;30(9):1038-45.

2. Bloch Thomsen PE, Jons $\mathrm{C}$, Raatikainen MJ, et al. Long-term recording of cardiac arrhythmias with an implantable cardiac monitor in patients with reduced ejection fraction after acute myocardial infarction: the Cardiac Arrhythmias and Risk Stratification After Acute Myocardial Infarction (CARISMA) study. Circulation. 2010;122(13):1258-64.

3. Sinno $H$, Derakhchan K, Libersan D, et al. Atrial ischemia promotes atrial fibrillation in dogs. Circulation. 2003;107(14):1930-6.

4. Worme MD, Tan MK, Armstrong DWJ, et al. Previous and New Onset Atrial Fibrillation and Associated Outcomes in Acute Coronary Syndromes (from the Global Registry of Acute Coronary Events). Am J Cardiol. 2018.

5. Jabre P, Roger VL, Murad $\mathrm{MH}$, et al. Mortality associated with atrial fibrillation in patients with myocardial infarction: a systematic review and meta-analysis. Circulation. 2011;123(15):1587-93.

6. Gonzalez-Pacheco H, Marquez MF, Arias-Mendoza A, et al. Clinical features and in-hospital mortality associated with different types of atrial fibrillation in patients with acute coronary syndrome with and without ST elevation. J Cardiol. 2015;66(2):148-54.

7. Braga CG, Ramos V, Martins J, et al. Impact of atrial fibrillation type during acute coronary syndromes: Clinical features and prognosis. Rev Port Cardiol. 2015;34(6):403-10.

8. Neumann F-J, Sousa-Uva M, Ahlsson A, et al. 2018 ESC/ EACTS Guidelines on myocardial revascularization. Eur Heart J. 2018:ehy394-ehy.

9. Jons C, Jacobsen UG, Joergensen RM, et al. The incidence and prognostic significance of new-onset atrial fibrillation in patients with acute myocardial infarction and left ventricular systolic dysfunction: a CARISMA substudy. Heart rhythm. 2011;8(3):342-8.

10. Akdemir R, Ozhan $\mathrm{H}$, Gunduz $\mathrm{H}$, et al. Effect of reperfusion on $\mathrm{P}$-wave duration and $\mathrm{P}$-wave dispersion in acute myocardial infarction: primary angioplasty versus thrombolytic therapy. Ann Noninvasive Electrocardiol.. 2005;10(1):35-40.

11. Siu C-W, Jim M-H, Ho H-H, et al. Transient Atrial Fibrillation Complicating Acute Inferior Myocardial Infarction. CHEST. 2007;132(1):44-9.

12. Consuegra-Sanchez L, Melgarejo-Moreno A, Galcera-Tomas $\mathrm{J}$, et al. Short- and long-term prognosis of previous and newonset atrial fibrillation in ST-segment elevation acute myocardial infarction. Revista espanola de cardiologia (English ed). 2015;68(1):31-8.

13. Kinjo $\mathrm{K}$, Sato $\mathrm{H}$, Sato $\mathrm{H}$, et al. Prognostic significance of atrial fibrillation/atrial flutter in patients with acute myocardial infarction treated with percutaneous coronary intervention. Am J Cardiol. 2003;92(10):1150-4.

14. Lopes RD, Elliott LE, White HD, et al. Antithrombotic therapy and outcomes of patients with atrial fibrillation following primary percutaneous coronary intervention: results from the APEX-AMI trial. Eur Heart J. 2009;30(16):2019-28.

15. Lin CJ, Liu CF, Kung CT, Sun CK, Lin YC, Leu S, et al. The prognostic value of atrial fibrillation on 30-day clinical outcome in patients with ST-segment elevation myocardial infarction undergoing primary percutaneous coronary intervention. Int Heart J. 2011;52(3):153-8.
16. Beukema RJ, Elvan A, Ottervanger JP, et al. Atrial fibrillation after but not before primary angioplasty for ST-segment elevation myocardial infarction of prognostic importance. Neth Heart J.. 2012;20(4):155-60.

17. Asanin M, Stankovic S, Mrdovic I, et al. B-type natriuretic peptide predicts new-onset atrial fibrillation in patients with ST-segment elevation myocardial infarction treated by primary percutaneous coronary intervention. Peptides. 2012;35(1):74-7.

18. Mrdovic I, Savic L, Krljanac G, et al. Incidence, predictors, and 30-day outcomes of new-onset atrial fibrillation after primary percutaneous coronary intervention: insight into the RISK-PCI trial. Coron artery dis. 2012;23(1):1-8.

19. Rene AG, Genereux P, Ezekowitz M, et al. Impact of atrial fibrillation in patients with ST-elevation myocardial infarction treated with percutaneous coronary intervention (from the HORIZONS-AMI [Harmonizing Outcomes With Revascularization and Stents in Acute Myocardial Infarction] trial). Am J Cardiol. 2014;113(2):236-42.

20. Gal P, Parlak E, Demirel F, et al. Prognostic significance of incident atrial fibrillation following STEMI depends on the timing of atrial fibrillation. Neth Heart J. 2015;23(9):430-5.

21. Zehir R, Tekkesin Al, Haykir N, et al. Peak troponin I level predicts new-onset atrial fibrillation in patients with myocardial infarction. Clin Invest Med.2016;39(6):E213-e9.

22. Karatas MB, Canga $Y$, Ipek $G$, et al. Association of admission serum laboratory parameters with new-onset atrial fibrillation after a primary percutaneous coronary intervention. Coron Artery dis. 2016;27(2):128-34.

23. Olsen FJ, Pedersen S, Jensen JS, Biering-Sorensen T. Global longitudinal strain predicts incident atrial fibrillation and stroke occurrence after acute myocardial infarction. Medicine. 2016;95(44):e5338.

24. Garg L, Agrawal S, Agarwal M, et al. Influence of Atrial Fibrillation on Outcomes in Patients Who Underwent Primary Percutaneous Coronary Intervention for ST-Segment Elevation Myocardial Infarction. Am J Cardiol. 2017.

25. Hwang KK, Eom SY, Lee SY, et al. Atrial Fibrillation on Admission Is Related With Higher Mortality in ST-Segment Elevation Myocardial Infarction Patients. Inte Heart J. 2017;58(4):48694.

26. Karabag Y, Rencuzogullari I, Cagdas M, et al. Association between BNP levels and new-onset atrial fibrillation : A propensity score approach. Herz. 2017.

27. Topaz G, Flint N, Steinvil A, et al. Long term prognosis of atrial fibrillation in ST-elevation myocardial infarction patients undergoing percutaneous coronary intervention. Int J Cardiol. 2017;240:228-33.

28. Podolecki T, Lenarczyk R, Kowalczyk J, et al. Significance of Atrial Fibrillation Complicating ST-Segment Elevation Myocardial Infarction. Am J Cardiol. 2017;120(4):517-21.

29. Rencuzogullari I, Cagdas M, Karakoyun S, et al. Propensity score matching analysis of the impact of Syntax score and Syntax score II on new onset atrial fibrillation development in patients with ST segment elevation myocardial infarction. Annals of noninvasive electrocardiology : the official journal of the International Society for Holter and Noninvasive Electrocardiology, Inc. 2017.

30. Rhyou HI, Park TH, Cho YR, et al. Clinical factors associated with the development of atrial fibrillation in the year following STEMI treated by primary PCI. J Cardiol. 2018;71(2):125-8.

31. Romanov $A$, Martinek $M$, Pürerfellner $H$, et al. Incidence of atrial fibrillation detected by continuous rhythm monitoring after acute myocardial infarction in patients with preserved left 
ventricular ejection fraction: results of the ARREST study. EP Europace. 2018;20(2):263-70.

32. Mazzone A, Scalese M, Paradossi U, et al. Development and validation of a risk stratification score for new-onset atrial fibrillation in STEMI patients undergoing primary percutaneous coronary intervention. Int J Clin Practice. 2018;72(4):e13087.

33. Modin D, Olsen FJ, Pedersen S, Jensen JS, Biering-Sorensen $\mathrm{T}$. Measures of left atrial function predict incident atrial fibrillation in STEMI patients treated with primary percutaneous coronary intervention. Int J Cardiol. 2018;263:1-6.

34. Asanin MR, Vasiljevic ZM, Matic MD et al. The Long-Term Risk of Stroke in Patients with Acute Myocardial Infarction Complicated with New-Onset Atrial Fibrillation. Clin Cardiol. 2009;32(8):467-70.

35. Zusman O, Amit G, Gilutz H, Zahger D. The significance of new onset atrial fibrillation complicating acute myocardial infarction. Clin Res Cardiol. 2012;101(1):17-22.

36. Bishara R, Telman G, Bahouth F, et al. Transient atrial fibrillation and risk of stroke after acute myocardial infarction. Thromb Haemost. 2011;106(5):877-84.
37. Guenancia C, Toucas C, Fauchier L, et al. High rate of recurrence at long-term follow-up after new-onset atrial fibrillation during acute myocardial infarction. Europace: European pacing, arrhythmias, and cardiac electrophysiology: journal of the working groups on cardiac pacing, arrhythmias, and cardiac cellular electrophysiology of the European Society of Cardiology. 2018.

38. Chaudhary N, Bundhun PK, Yan H. Comparing the clinical outcomes in patients with atrial fibrillation receiving dual antiplatelet therapy and patients receiving an addition of an anticoagulant after coronary stent implantation: A systematic review and meta-analysis of observational studies. Medicine. 2016;95(50):e5581.

39. Gibson CM, Mehran R, Bode C, et al. Prevention of Bleeding in Patients with Atrial Fibrillation Undergoing PCl. N Engl J Med. 2016;375(25):2423-34.

40. Cannon CP, Bhatt DL, Oldgren J, et al. Dual Antithrombotic Therapy with Dabigatran after $\mathrm{PCl}$ in Atrial Fibrillation. N Engl J Med2017;377(16):1513-24. 